cap-shaped end of which the cervix sits, firmly held. (And herej I would claim that there is a decided advantage in being able to dispense with, in many cases, the ponderous prehension forceps generally used for elevating uterine fibroids through the abdominal wound during operation, and

Frg. 2.

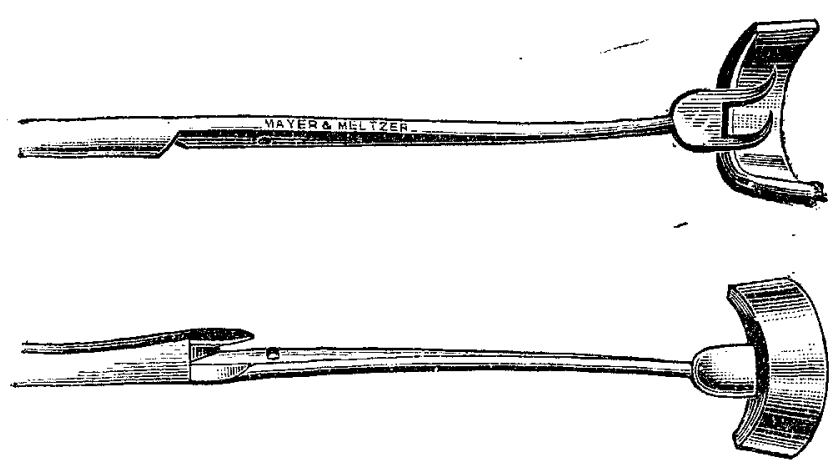

Forceps with blades unlocked.

Bo preventing the annoying hæmorrhage which sometimes takes place from forceps punctures of such tumours.) The broad ligaments were divided between two rows of ligatures, and the usual peritoneal flaps dissected down off the anterior and posterior surfaces of the uterus with blunt scissors and finger. The aterine arteries were now easily picked up on an aneurysm needle and secured outside the reflected peritoneum. The vagina was opened by running a knife around the cervix, within the hollow of the vaginal director, which was still steadied by an assistant and easily felt. Now, instead of suturing the peritoneal flaps as I have done in previous cases, I passed about half a dozen long silk sutures through the edges of the peritoneal flaps and drew them into the vagina, thus completely closing the peritoneal floor. With a Sims speculum the vagina was now well packed with dodoform gauze, firm traction being kept on the flap sutures during the packing. The abdominal wound was closed with deep silkworm gut and superficial horsehair sutures. The vaginal packing was removed on the fourth day after operation, and the sutures on the eighth day. The patient made a perfect recovery and left the hospital on Aug. 27th, 1896.

Melbourne.

\section{A CASE OF HEMICHOREA WITH APHASIA.}

By S. J. ROSS, M.B., CH.B. VICT.,

RESIDENT HOUSE SURGEON, BEDFORD GENERAI INFIRMARY AND FEVER HOSPITAL.

A GIRL, aged fourteen years, at the age of eight years had had an attack of acute rheumatism which left traces behind in the form of well-marked mitral regurgitation. A week kefore being seen she was thrown from a cart, and on the day following the accident her mother noticed that her right arm and leg were constantly in motion and she was restless and never answered questions put to her. Thinking "she was merely shaken" she was put to bed, her parents hoping that by taking rest she would soon be well again. However, as she did not improve I was asked to see her seven days after her fall from the cart. Her condition at this time was as follows. She was in a condition of marked cerebral instability, now laughing and the next minute in tears. Her pupils were dilated. There were marked choreiform movements in the right arm and leg. The tongue was protruded with a jerk and as suddenly withdrawn. The knee-jerk on the right side was exaggerated ; on the left side it was normal. Sensation was normal. There were marked cardiac irregudarity and a mitral systolic murmur conducted to the back, with accentuation of the pulmonary second sound. On being asked questions the patient simply nodded assent or dissent. The movements ceased during sleep.

The treatment adopted was absolute rest, milk only, arsenical solution in increasing doses-as diet at one time she was taking ten minims three times a dayand occasional purgatives. In six weeks she was on full diet and had perfectly regained her power of speech.

Rerarks.-A case such as this points clearly to the cerebral origin of the lesion. The emotion and cessation of movements during sleep, the exaggerated right knee-jerk and aphasia, point clearly to a lesion on the left side of the brain, not permanent, but functional, or at any rate capable of complete resolution. What the exact pathological cbange may be is not known, and, indecd, we must be left in doubt as chorea is a disease so amenable to treatment. Gowers suggests a lowered resistance on the part of the cerebral cells. If this be true it is curious that in cases such as this of true hemichorea this lowered resistance should be limited to the cells on one side of the brain. Others bave suggested a rheumatic inflammation of the cerebral neuroglia - a neurogliosis-these nodules corresponding to the periosteal nodes so frequertly found along bones such as the tibia. Whatever the exact pathological change may be it is certainly curious that arsenic should have absolute control over it-a control which no other drug possesses, except, perhaps, in those cases of convalsive or epileptiform varieties of chorea when a combination of chloral bydrate and bromide of potassium is the most successful treatment, at any rate at first, arsenic frequently being resorted to after the convulsive stage has passed. In offering these remarks of course I do not include that form of nervous disturbance which is often called post-hemiplegic chorea, but which ought rather to be called post-hemiplegic mobile spasm, as suछgested by Gowers.

\section{A CASE OF OBSTRUCTIVE SUPPRESSION OF URINE.}

By F. GRAHAM CROOKSHANK, M D. LOND, LATE HOJSE PHYSICIAN TO THE BROMPTON HOSPITAL.

A LITTLE girl, aged eleven years, was brought to the Brompton Hospital for Consumption and Diseases of the Chest in a state of collapse, the mother stating that almost incessant romiting had occurred for a week; the bowels had been confined during that period. The aspect was suggestively abdominal, and the case appeared to be one of intestinal obstruction. The patient was at once admitted under Dr. Green, who has most kindly allowed me to write this account. The more complete examination then possible failed to detect any abdominal tumour or evidence of peritonitis. The child, although drowsy, was quite conscious; the temperature in the axilla was $96^{\circ} \mathrm{F}$.; the pulse 120 per minute, small and thready; and the respirations were 25 per minute and shallow. On auscultation an apical systolic bruit and moist râles, with friction sounds at the posterior bases of both lungs, were heard. There was no odema. Spasms of the levatores palpebrarum and internal recti occurred every few minutes, bat no other muscular twitchings were noted. The tongue was very foul and the breath was urinous. Further inquiry elicited the fact that three years previously an operation-details of which I have been unable to ascertain-was performed for an abscess of the right kidney. Two years previously there had been a severe illness, lasting several days, the prominent feature of which was agonising pain in the loin. For the last ten days or so there had been much headache, and for a week frequent vomiting. For at least five days prior to admission no urine had been passed, and for several months previously the child had passed urine only at comparatively long intervals (twenty-four hours or more), and then with pain. During the night after admission seven and a half ounces of turbid urine were passed. The urine was acid, of specific gravity 1020, gave a heavy precipitate with picric acid solution, and contained many pus cells, but was without either casts or blood. No more urine was passed during life, and after death the bladder was found to be empty. Vomiting occurred four or five times during the following day, and the spasms of the ocular muscles happened as frequently as before. The pupils were equal and slightly dilated. The child rallied slightly on the whole; the pulse improved, and the rectal temperature rose to $98^{\circ}$, and subsequently to $100^{\circ}$. Towards night the respirations, which had been tranquil, became bissing in cbaracter, and the rate rose to 30 or 35 per minute. The drowsiness increased at the same time. By the early morning these symptoms had passed off, but only to recur with greater severity for an hour or two before death, which took place rather suddenly 